\title{
KARAKTERISASI MODUL CYCLICALLY PURE (CP)-INJEKTIF
}

\author{
Nia Yulianti ${ }^{1 *}$, Hanni Garminia $\mathrm{Y}^{2}$ \\ ${ }^{1}$ Politeknik Siber dan Sandi Negara \\ ${ }^{2}$ Institut Teknologi Bandung \\ Email: nia.yulianti@poltekssn.ac.id,
}

\begin{abstract}
This research deals with the structure of cyclically pure injective modules over a commutative ring $R$. If $I$ be an ideal of $R$, proved that any $C P$-injective $R / I$ modul is also $C P$-injective as an $R$-module. The main result of research is the existance of $C P$-injective $R$-module if there is an $R$-module. More over, we deal characterization of $C P$-injective module which is related to proper essential ctclically pure extension. It is shown that $R$-modul $D$ is cyclically pure injective if and only if $D$ has no proper essential cyclically pure extension.
\end{abstract}

Keywords: exact sequence, $C P$-injective, essensial extension, direct summand, injective module

\begin{abstract}
Abstrak. Penelitian ini membahas dan menyajikan mengenai struktur dari modul $C P$ injektif atas gelanggang komutatif $R$. Jika $I$ adalah ideal dari $R$, ditunjukkan bahwa sebarang $R / I$-modul $C P$-injektif juga merupakan $R$-modul $C P$-injektif. Hasil utama penelitian ini adalah eksistensi dari $R$-modul $C P$ injektif jika diketahui suatu $R$ modul. Lebih jauh lagi, dilakukan karakterisasi modul $C P$-injektif terkait dengan essensial $C P$-extension sejati. Akan ditunjukkan suatu $R$-modul $D$ merupakan $C P$ injektif jika dan hanya jika $D$ tidak memiliki essensial $C P$-extension sejati.
\end{abstract}

Kata Kunci: barisan eksak, $C P$-injektif, essential extension, jumlah langsung, modul injektif.

\section{PENDAHULUAN}

Konsep modul pure injektif memiliki peranan penting pada Aljabar Komutatif. Aplikasi dari modul pure injektif juga diterapkan pada Teori Flat Covers [1]. Konsep modul cyclically pure injektif ( $C P$-Injektif) merupakan salah satu generalisasi dari konsep modul pure injektif. L. Melkersson [2] mengkaji beberapa karakterisasi modul $M$ yang dibangun secara hingga atas gelanggang lokal Noetherian yang pure pada setiap $C P$-ekstension dari $M$ dengan memanfaatkan konsep $C P$-injektif.

Dalam penelitian matematika, biasanya suatu dugaan akan muncul dengan membandingkan sifat-sifat yang telah dihasilkan pada pengkajian lain dari objek yang serupa. Berdasarkan metode tersebut, merupakan suatu hal yang lumrah jika muncul kemungkinan pengembangan sifat modul $C P$-injektif terkait $C P$-ekstension. Khususnya, pengkajian terhadap permasalahan yang muncul dalam usaha menjawab apakah suatu modul $C P$-injektif jika dan hanya jika modul tersebut tidak memiliki essential CP-ekstension sejati.

Referensi yang menjadi rujukan utama yang digunakan dalam penelitian ini adalah Some Criteria of Cyclically Pure Injective Modules yang ditulis oleh Kamran Divaani-Aazar, Mohammad Ali Esmkhani, dan Massoud Tousi (cetakan tahun 2005). Alur penulisan, cara pan- 
dang, dan pembuktian sifat-sifat dalam tesis ini disajikan dalam rumusan dan organisasi yang berbeda dari pustaka utama, dengan tujuan untuk memberikan inspirasi dan arahan yang lebih jelas bagi pengembangannya di teori modul.

\section{KARAKTERISASI MODUL CP-INJEKTIF}

\subsection{HOMOMORFISMA DAN BARISAN EKSAK}

Berdasarkan modul atas gelanggang $R$ dan homomorfisma dari suatu $R$-modul maka dapat dibentuk suatu barisan yang disebut sebagai barisan eksak [3], dijelaskan pada definisi berikut ini

Definisi 1 [5] Misalkan $R$ adalah gelanggang dan $n \in \mathbb{N} \geq 3$. Barisan

$$
M_{1} \stackrel{\varphi_{1}}{\longrightarrow} M_{2} \stackrel{\varphi_{2}}{\longrightarrow} \ldots \stackrel{\varphi_{n-1}}{\longrightarrow} M_{n}
$$

dengan $M_{1}, \ldots, M_{n}$ adalah $R$-modul dan homomorfisma $R$-modul $\varphi_{i}: M_{i} \longrightarrow M_{i+1}$ untuk $i=1, \ldots, n-1$ disebut eksak pada posisi ke $i \in 2, \ldots, n-1$ jika $i m \varphi_{i-1}=k e r \varphi_{i}$. Kemudian disebut barisan eksak jika eksak pada setiap posisi $i \in 2, \ldots, n-1$.

Definisi 2 [4] Misalkan $R$ adalah gelanggang dan $A, B, C$ adalah suatu $R$-modul. Barisan eksak $0 \longrightarrow A \longrightarrow B \longrightarrow C \longrightarrow 0$ dikatakan $C P$ jika pemetaan natural

$$
R / I \otimes_{R} A \longrightarrow R / I \otimes_{R} B
$$

injektif untuk semua ideal I dari $R$ yang dibangun secara hingga.

Barisan eksak- $C P$ ini memegang peranan penting ketika akan mengkontrusi modul $C P$ injektif. Selain itu, juga diperlukan monomorfisma- $C P$ yang didefinisikan sebagai berikut.

Definisi 3 [4] Misalkan $R$ adalah gelanggang dan $A, B$ adalah suatu $R$-modul. $R$-monomorfisma $f: A \longrightarrow B$ dikatakan $C P$ jika barisan eksak

$$
0 \longrightarrow A \stackrel{f}{\rightarrow} B \stackrel{\text { nat }}{\longrightarrow} B / f(A) \longrightarrow 0
$$

$C P$.

Selanjutnya definisi ini dipakai dalam mengkontruksi modul $C P$-injektif dan mengkarakterisasi modul $C P$-injektif terkait essensial $C P$-extension sejati.

\subsection{Eksistensi Modul CP-Injektif}

Setelah mengenal barisan eksak $C P$ dan $R$-monomorfisma $C P$ kita dapat mendefinisikan modul $C P$-injektif sebagai berikut.

Definisi 4 [4] Misalkan $R$ adalah suatu gelanggang. Suatu modul $D$ atas $R$ dikatakan $C P$ Injektif jika untuk sebarang barisan eksak CP

$$
0 \longrightarrow A \longrightarrow B \longrightarrow C \longrightarrow 0
$$


barisan terinduksi

$$
0 \longrightarrow \operatorname{Hom}_{R}(C, D) \longrightarrow \operatorname{Hom}_{R}(B, D) \longrightarrow \operatorname{Hom}_{R}(A, D) \longrightarrow 0
$$

eksak.

Misalkan $E_{i}$ adalah kelas dari $R$-modul maka $\prod_{i \in I} E_{i}$ merupakan $R$-modul injektif jika dan hanya jika $E_{i}$ injektif untuk setiap $i \in I$ [7]. Dengan memanfaatkan hasil ini, bisa memperoleh kesimpulan yang analog untuk modul $C P$-injektif. Hal ini dibuktikan pada lemma berikut.

Lemma 1 [4] Misalkan $\left\{D_{i}\right\}_{i \in I}$ adalah kelas dari R-modul. Maka $\prod_{i \in I} D_{i}$ adalah CP-Injektif $R$-modul jika dan hanya jika $D_{i} C P$-Injektif untuk semua $i \in I$.

Misalkan $R$ adalah gelanggang dan $I$ adalah ideal dari $R$. Modul $D$ dapat dipandang sebagai modul atas $R$ jika $D$ merupakan suatu modul atas $R / I$. Sebaliknya modul $D$ dapat dipandang sebagai modul atas $R / I$ jika $D$ merupakan suatu modul atas $R$ dengan $I D=0$. Untuk lebih Jelasnya disajikan pada Lemma 2 berikut.

Lemma 2 [4] Misalkan $R$ adalah gelanggang, I adalah ideal dari $R$. modul D merupakan $R / I$-modul jika dan hanya jika $D$ adalah suatu $R$-modul dengan $I D=0$.

Selanjutnya lemma tersebut dapat dimanfaatkan untuk mengkontruksi sifat yang analog terkait modul $C P$-injektif. Sebelumnya diberikan sifat eksistensi suatu $R / I$-homomorfisma jika diketahui suatu $R$-homomorfisma. Buktinya disajikan pada lemma berikut.

Lemma 3 Misalkan $f: N \longrightarrow M$ adalah R-homomorfisma, maka terdapat suatu $R / I$ homomorfisma $f^{\prime}: N \longrightarrow M$.

Bukti. Definisikan

$$
\begin{aligned}
f^{\prime}: N & \longrightarrow M \\
n & \longmapsto f(n) .
\end{aligned}
$$

Akan ditunjukkan $f^{\prime}$ adalah suatu $R / I$-homomorfisma.

1. Ambil sebarang $n_{1}, n_{2} \in N_{R / I}$. Sehingga

$$
\begin{aligned}
f^{\prime}\left(n_{1}+n_{2}\right) & =f\left(n_{1}+n_{2}\right) ; \\
& =f\left(n_{1}\right)+f\left(n_{2}\right) ; \\
& =f^{\prime}\left(n_{1}\right)+f^{\prime}\left(n_{2}\right) .
\end{aligned}
$$


2. Ambil sebarang $r+I \in R / I$ dan $n \in N_{R / I}$. Sehingga

$$
\begin{aligned}
f^{\prime}((r+I) . n) & =f((r+I) \cdot n) ; \text { karena } \operatorname{In}=0 ; \\
& =f(r n+I n) ; \\
& =f(r n) ; \\
& =r f(n)+\operatorname{If}(n) ; \operatorname{If}(n)=0 ; \\
& =(r+I) f^{\prime}(n+\operatorname{In}) ; \\
& =(r+I) f^{\prime}(n) .
\end{aligned}
$$

Dari $(i)$ dan $(i i)$ terbukti bahwa $f^{\prime}$ merupakan suatu $R / I$-homomorfisma.

Berikut diberikan suatu teorema yang menyatakan bahwa jika $M$ adalah suatu modul $C P$ injektif atas gelanggang $R / I$ maka $M$ juga suatu modul $C P$-injektif atas gelanggang $R$.

Teorema 1 Misalkan $M$ adalah $R / I$-modul $C P$-injektif maka $M$ adalah $R$-modul $C P$-injektif dengan I adalah ideal dari gelanggang $R$.

Bukti. Akan ditunjukkan $M$ adalah modul $C P$-injektif atas gelanggang $R$. Ambil sebarang barisan eksak

$$
0 \longrightarrow A_{R} \stackrel{f}{\rightarrow} B_{R} \stackrel{g}{\rightarrow} C_{R} \longrightarrow 0
$$

Akan ditunjukkan

$$
0 \longrightarrow H_{\text {om }}(C, M) \longrightarrow H_{\text {om }}(B, M) \longrightarrow H_{R}(A, M) \longrightarrow 0
$$

eksak.

Diketahui $M$ adalah $R / I$-modul $C P$-injektif. Akan ditunjukkan sebarang

$$
0 \longrightarrow A_{R / I} \stackrel{f^{\prime}}{\rightarrow} B_{R / I} \stackrel{g^{\prime}}{\rightarrow} C_{R / I} \longrightarrow 0
$$

eksak $C P$.

1. Akan ditunjukkan

$$
0 \longrightarrow A_{R / I} \stackrel{f^{\prime}}{\rightarrow} B_{R / I} \stackrel{g^{\prime}}{\rightarrow} C_{R / I} \longrightarrow 0
$$

merupakan barisan eksak.

(a) Akan ditunjukkan $f^{\prime}$ injektif. Ambil $x \in k e r\left(f^{\prime}\right) \subseteq A_{R / I}$. Diperoleh

$$
\begin{aligned}
0 & =f^{\prime}(x) \\
& =f(x) .
\end{aligned}
$$

Sehingga $x \in \operatorname{ker}\left(f^{\prime}\right)=0$. Akibatnya $x=0$ dan $\operatorname{ker}\left(f^{\prime}\right)=0$. Jadi terbukti $f^{\prime}$ injektif.

(b) Akan ditunjukkan $g^{\prime}$ surjektif. Ambil sebarang $c_{1} \in C_{R}$. Karena $g$ surjektif maka terdapat $b \in B_{R}$ sehingga $c_{1}=g\left(b_{R}\right)=g^{\prime}\left(b_{R / I}\right)$. Jadi terbukti $g^{\prime}$ surjektif. 
(c) Akan ditunjukkan $\operatorname{Im} f^{\prime}=k e r g^{\prime}$.

i. Akan ditunjukkan $i m f^{\prime} \subseteq k e r g^{\prime}$. Ambil $x \in i m f^{\prime}$ maka terdapat $y \in A_{R} / I$ sehingga $x=f^{\prime}\left(y_{R / I}\right)=f\left(y_{R}\right) \in i m f=k e r g$. Sehingga

$$
\begin{aligned}
g\left(x_{R}\right) & =0 ; \\
g^{\prime}\left(x_{R / I}\right) & =0 .
\end{aligned}
$$

Akibatnya $x \in k e r g^{\prime}$. Jadi $i m f^{\prime} \subseteq k e r g^{\prime}$.

ii. Akan ditunjukkan $k e r g^{\prime} \subseteq i m f^{\prime}$. Ambil $x \in k e r g^{\prime}$ maka $0=g^{\prime}\left(x_{R / I}=\right.$ $\left.g\left(x_{R}\right)\right)$. Akibatnya $x \in \operatorname{kerg}=i m f$ maka terdapat $y \in A_{R}$ sehingga, $x+f\left(y_{R}\right)=f^{\prime}\left(y_{R / I}\right) \in i m f^{\prime}$. Jadi $k e r g^{\prime} \subseteq i m f^{\prime}$.

Jadi terbukti $i m f^{\prime}=k e r g^{\prime}$.

Jadi, terbukti $0 \longrightarrow A_{R / I} \stackrel{f^{\prime}}{\rightarrow} B_{R / I} \stackrel{g^{\prime}}{\rightarrow} C_{R / I} \longrightarrow 0$ merupakan barisan eksak.

2. Akan ditunjukkan barisan $0 \longrightarrow A_{R / I} \stackrel{f^{\prime}}{\rightarrow} B_{R / I} \stackrel{g^{\prime}}{\rightarrow} C_{R / I} \longrightarrow 0$ merupakan barisan eksak- $C P$.

Akan ditunjukkan pemetaan natural $h: R / I / a \otimes_{R / I} A_{R / I} \longrightarrow R / I / a \otimes_{R / I} B_{R / I}$ injektif untuk setiap ideal $a$ dari $R / I$.Ambil $(\bar{r}+a) \otimes_{R / I} n k e r h \subseteq R / I / a \otimes_{R / I} A_{R / I}$, maka

$$
\begin{aligned}
h\left((\bar{r}+a) \otimes_{R / I} t\right) & =\left(a \otimes_{R / I} 0_{B}\right) ; \\
\bar{r}_{1}+a \otimes_{R / I} f^{\prime}(t) & =a \otimes_{R_{I}} 0_{B} .
\end{aligned}
$$

Perhatikan bahwa $\overline{r_{1}}+a=a=0_{R / I / a}$ dan $f^{\prime}(t)=0_{B}$.

Karena $f^{\prime}$ injektif, maka $t=0_{A}$. Sehingga $\overline{r_{1}}+a \otimes_{R / b} t=a \otimes_{R / b} 0_{A}$. Jadi $h$ injektif. Terbukti barisan

$$
0 \longrightarrow A_{R / I} \stackrel{f^{\prime}}{\rightarrow} B_{R / I} \stackrel{g^{\prime}}{\rightarrow} C_{R / I} \longrightarrow 0
$$

merupakan barisan eksak- $C P$.

Diperoleh $0 \longrightarrow A_{R / I} \stackrel{f^{\prime}}{\rightarrow} B_{R / I} \stackrel{g^{\prime}}{\rightarrow} C_{R / I} \longrightarrow 0$ barisan eksak $C P$.

Maka barisan $0 \longrightarrow \operatorname{Hom}_{R / I}(C, M) \stackrel{\rho^{\prime}}{\rightarrow} \operatorname{Hom}_{R / I}(B, M) \stackrel{\tau^{\prime}}{\rightarrow} \operatorname{Hom}_{R / I}(A, M) \longrightarrow 0$ eksak.

Selanjutnya akan ditunjukkan barisan

$$
0 \longrightarrow \operatorname{Hom}_{R}(C, M) \stackrel{\rho}{\rightarrow} \operatorname{Hom}_{R}(B, M) \stackrel{\tau}{\rightarrow} \operatorname{Hom}_{R}(A, M) \longrightarrow 0
$$

eksak.

1. Akan ditunjukkan $\rho$ injektif. Ambil $\phi \in \operatorname{ker} \rho$ maka $\rho(\phi)=0$. Untuk setiap $b \in B$, maka

$$
\begin{aligned}
\rho(\phi)(b) & =0 ; \\
\rho^{\prime}\left(\phi^{\prime}\right)(b) & =0 .
\end{aligned}
$$

Sehingga $\phi^{\prime} \in k e r \rho^{\prime}$. Karena $\rho^{\prime}$ injektif maka $\phi^{\prime}=0$, akibatnya $\phi=0$. Sehingga $\operatorname{ker} \rho=$ 0. Jadi terbukti $\rho$ injektif. 
2. Akan ditunjukkan $\tau$ surjektif. Ambil sebarang $\sigma \in \operatorname{Hom}_{R}(A, M)$. Karena $\tau^{\prime}$ surjektif maka terdapat $\alpha \in \operatorname{Hom}_{R / I}(B, M)$. Sehingga $\tau^{\prime}(\alpha)=\sigma^{\prime}, \sigma^{\prime} \in \operatorname{Hom}_{R / I}(A, M)$.

Perhatikan bahwa:

$$
\begin{aligned}
\sigma((r+I) a) & =\sigma(r a+I a) ; \\
& =\sigma(r a) ; \\
& =r \cdot \sigma(a) ; \\
& =r \cdot \sigma(a)+I \sigma(a) ; \\
& =(r+I) \sigma(a) ; \\
& =(r+I) \sigma^{\prime}(a) .
\end{aligned}
$$

Jadi, $\sigma=\sigma^{\prime}$ Akibatnya $\sigma=\sigma^{\prime}=\tau^{\prime}(\alpha)=\tau(\alpha)$ dengan $\alpha \in \operatorname{Hom}_{R}(B, M)$ Jadi terbukti $\tau$ surjektif.

3. Akan ditunjukkan $i m \rho=k e r \tau$.

(a) Akan ditunjukkan $i m \rho \subseteq k e r \tau$. Ambil $\alpha \in i m \rho$ maka $\exists \gamma \in \operatorname{Hom}_{R}(C, M)$ sehingga

$$
\begin{aligned}
\rho(\gamma) & =\alpha \\
\rho^{\prime}(\gamma) & =\alpha
\end{aligned}
$$

Perhatikan bahwa $\alpha \in i m \rho^{\prime}=k e r \tau^{\prime}$ sehingga $\tau^{\prime}(\alpha)=0$ dan $\tau(\alpha)=0$. Akibatnya $\alpha \in k e r \tau$. Jadi $i m \rho \subseteq k e r \tau$.

(b) Akan ditunjukkan $k e r \tau \subseteq i m \rho$. Ambil $\alpha \in k e r \tau$ maka

$$
\begin{aligned}
\tau(\alpha) & =0 \\
\tau^{\prime}(\alpha) & =0
\end{aligned}
$$

Sehingga $\alpha \in k e r \tau^{\prime}=i m \rho^{\prime}$ maka terdapat $\left.\gamma \in \operatorname{Hom}_{(} R / I\right)(B, M)$ sehingga $\alpha=\rho^{\prime}(\gamma)=\rho(\gamma)$. Akibatnya $\left.\alpha \in i m \rho\right)$. Jadi $\operatorname{ker} \tau \subseteq i m \rho$.

Jadi terbukti $\operatorname{Im} \rho=\operatorname{Ker} \tau$.

Jadi terbukti barisan $0 \longrightarrow H_{R}(C, M) \stackrel{\rho}{\rightarrow} \operatorname{Hom}_{R}(B, M) \stackrel{\tau}{\rightarrow} \operatorname{Hom}_{R}(A, M) \longrightarrow 0$ eksak.

Teorema berikut menjamin eksistensi modul $C P$-injektif jika diketahui suatu modul atas gelanggang $R$.

Teorema 2 Jika $M$ adalah suatu R-modul maka terdapat suatu CP-Injektif R-modul D.

Bukti. Misalkan $R^{*}$ menotasikan himpunan semua ideal $R$ yang dibangun secara hingga yaitu $R^{*}=\{a \subseteq R \mid a$ ideal yang dibangun secara hingga $\}$.

Misalkan

$$
D=P i_{a \in R^{*}} E_{R / a}(M / a M)
$$

dengan $E_{R / a}(M / a M)$ adalah injective envelope dari $R / a$-modul $M / a M$. 
1. Diketahui $E_{R / a}(M / a M)$ adalah injective envelope $R / a$-modul $M / a M$. artinya pernyataan-pernyataan berikut ekivalen [8].

(a) Maximal essential extension dari $M / a M$ adalah $E_{R / a}(M / a M)$.

(b) Minimal injective submodul dari $E^{\prime} \supseteq E_{R / a}(M / a M)$ yang memuat $M / a M$ adalah $E_{R / a}(M / a M)$.

(c) Essential extension dari $M$ adalah $E_{R / a}(M / a M)$ dan merupakan modul injektif.

2. Akan ditunjukkan $M / a M$ adalah $R / a$-modul. Akan diperiksa apakah $M / a M$ suatu $R$ modul. Ambil $r, s \in R, m+a M, n+a M \in M / a M$. Definisikan aksi $R$ pada $M / a M$ yaitu

$$
r .(m+a M)=r m+a M
$$

(a) Akan ditunjukkan aksi tersebut well define. Misalkan $r=s$ dan $m=n$ sehingga

$$
\begin{aligned}
r m & =s n ; \\
r m-s n & =0 \in a M .
\end{aligned}
$$

Akibatnya

$$
\begin{aligned}
r m+a M & =s n+a M ; \\
r(m+a M) & =s(n+a M) .
\end{aligned}
$$

Jadi, terbukti aksinya well define.

(b) Ambil sebarang $r, s \in R$ dan $m+a M, n+a M \in M / a M$ sehingga:

i.

$$
\begin{aligned}
(r s)(m+a M) & =(r s m)+a M ; \\
& =r(s m)+a M ; \\
& =r(s m+a M) .
\end{aligned}
$$

ii.

$$
\begin{aligned}
r((m+a M)+(n+a M) & =r((m+n)+a M) ; \\
& =r(m+n)+a M ; \\
& =r m+r n+a M ; \\
& =(r m+a M)+(r n+a M) ; \\
& =(m+a M)+r(n+a M) .
\end{aligned}
$$

iii.

$$
\begin{aligned}
(r+s)((m+a M) & =(r+s) m+a M \\
& =r m+s m+a M \\
& =(r m+a M)+(s m+a M) \\
& =r(m+a M)+s(m+a M)
\end{aligned}
$$


iv.

$$
\begin{aligned}
1 .(m+a M) & =1 m+a M ; \\
& =m+a M .
\end{aligned}
$$

Jadi, $M / a M$ adalah $R$-modul.

Akibatnya, $M / a M$ adalah $R / a$-modul.

Definisikan

$$
\begin{aligned}
\varphi: M & \longrightarrow D \\
& \longmapsto(x+a M)_{a} \in\left(R^{*}\right) \quad \forall x \in M
\end{aligned}
$$

1. Akan ditunjukkan $\varphi$ adalah $R$-homomorfisma.

(a) Ambil sebarang $x, x_{1} \in M$ dan $r \in R$, maka

$$
\begin{aligned}
\varphi\left(x_{1}+x_{2}\right) & =\left(x_{1}+x_{2}\right)+a M ; \\
& =\left(x_{1}+a M\right)+\varphi\left(x_{2}+a M\right) ; \\
& =\varphi\left(x_{1}\right)+\varphi\left(x_{2}\right) .
\end{aligned}
$$

(b) Ambil sebarang $r \in R$ dan $x \in M$, maka

$$
\begin{aligned}
\varphi(r x) & =r x+a M ; \\
& =r(x+a M) ; \\
& =r \varphi(x) .
\end{aligned}
$$

Jadi $\varphi$ adalah $R$-homomorfisma.

2. Akan ditunjukkan $E_{R / a}(M / a M) C P$ injektif $R / a$-modul. Ambil sebarang barisan $0 \longrightarrow$ $A_{R / a} \stackrel{p}{\rightarrow} B_{R / a} \stackrel{q}{\rightarrow} C_{R / a} \longrightarrow 0 C P$. Akan ditunjukkan $0 \longrightarrow H_{R} / a\left(C, E_{R / a}(M / a M)\right) \stackrel{f}{\rightarrow}$ $\operatorname{Hom}_{R / a}\left(B, E_{R / a}(M / a M)\right) \stackrel{g}{\rightarrow} \operatorname{Hom}_{R}\left(A, E_{R / a}(M / a M)\right) \longrightarrow 0$ eksak.

$$
\begin{array}{r}
\psi: C \longrightarrow E_{R / a}(M / a M) \\
f(\psi): B \longrightarrow E_{R / a}(M / a M)
\end{array}
$$

$f(\psi)=\psi \circ q: B \longrightarrow E$

(a) Akan ditunjukkan $f$ injektif. Ambil $\psi \in \operatorname{ker}(f) \subseteq \operatorname{Hom}_{R / a}\left(C_{B}, E_{R / a}(M / a M)\right)$, 
maka untuk setiap $b \in B$ dan $c \in C$

$$
\begin{aligned}
f(\psi) & =0_{\text {Hom }(B, E)} ; \\
f(\psi) b & =0(b) \\
f(\psi)(b) & =0_{E} ; \\
(\psi \circ q)(b) & =0_{E} ; \\
(\psi)(q(b)) & =0_{E} ; \\
\psi(c) & =0_{E}, \text { karena } q \text { surjektif untuk setiap } c \in C ; \\
\psi & =0_{\operatorname{Hom}(C, E) .}
\end{aligned}
$$

Sehingga $\operatorname{ker}(f)=0$. Jadi terbukti $f$ injektif.

(b) Akan ditunjukkan $g$ surjektif. Definisikan

$$
\begin{aligned}
g: \operatorname{Hom}_{R / a}\left(B, E_{R / a}(M / a M)\right) & \longrightarrow H_{o m} / a \\
\tau & \longmapsto \tau_{p}
\end{aligned}
$$

Akan ditunjukkan $g$ pemetaan. Ambil sebarang $\tau_{1}=\tau_{2}$. Karena $p$ injektif dan $\tau_{1}=\tau_{2}$ maka $g\left(\tau_{1}\right)=g\left(\tau_{2}\right)$. Jadi $g$ pemetaan. Karena $E_{R / a}(M / a M)$ modul injektif artinya untuk setiap $\varphi \in \operatorname{Hom}(A, E)$ terdapat $\theta$ sehingga $\varphi=\theta p$. Akibatnya terdapat $\theta \in \operatorname{Hom}(B, E)$ sehingga $g(\theta)=\theta p=\varphi$. Jadi terbukti $g^{\prime}$ surjektif.

(c) Akan ditunjukkan $\operatorname{Imf}=K \mathrm{Kerg}$

i. Akan ditunjukkan $\operatorname{Im} f \subseteq \operatorname{Kerg}$. Ambil $\theta \in \operatorname{Imf}$. Akan ditunjukkan $\theta \in$ Kerg. $\theta \in \operatorname{Imf}$, maka terdapat $\psi \in \operatorname{Hom}(C, E)$ sehingga

$$
\begin{gathered}
f(\psi)=\theta ; \\
\psi q=\theta . \\
g(\theta)=\theta p ; \\
=\psi q p . \\
q(\theta)(a)=\psi q p(a) ; \\
=\psi q(p(a)) .
\end{gathered}
$$

Karena $p(a) \in \operatorname{Imp}=\operatorname{Ker} q$ maka $q p(a)=0$. Akibatnya $g(\theta)(a)=\psi 0=0$. Sehingga $\theta \in K$ Kerg. Jadi $\operatorname{Im} f \subseteq K e r g$.

ii. Akan ditunjukkan Kerg $\subseteq \operatorname{Imf}$. Ambil sebarang $\theta \in K e r g$. Akan ditunjukkan $\theta \in \operatorname{Imf}$. Karena $E_{R / a}(M / a M)$ modul injektif, artinya untuk setiap $\theta \in \operatorname{Hom}(B, E)$ terdapat $\psi$ sehingga $\theta=\psi q$.

Perhatikan:

$$
\begin{aligned}
f: \operatorname{Hom}\left(C, E_{R / a}(M / a M)\right) & \longrightarrow \operatorname{Hom}\left(B, E_{R / a}(M / a M)\right) \\
\tau & \longmapsto \tau_{q}
\end{aligned}
$$


Akan ditunjukkan $f$ injektif.

$$
\begin{aligned}
f(\tau) & =0 ; \\
\tau q & =0 ; \\
\tau q(b) & =0_{b} ; \text { untuk setiap } b \in B ; \\
\tau & =0 .
\end{aligned}
$$

Akibatnya $f$ injektif sehingga $\theta \in \operatorname{Im} f$. Jadi $\operatorname{Ker} g \subseteq \operatorname{Imf}$.

Jadi terbukti $\operatorname{Imf}=\operatorname{Kerg}$.

Jadi, $E_{R / a}(M / a M)$ merupakan $C P$-injektif $R / a$-modul.

Berdasarkan Lemma $1 D=\prod_{a \in R^{*}} E_{R / a}(M / a M)$ juga $C P$-injektif $R / a$-modul dan berdasarkan Teorema $1 D$ adalah $C P$-injektif $R$-modul.

\subsection{Karakterisasi Modul CP-Injektif}

Sebelumnya dijelaskan beberapa definisi dan sifat-sifat yang terkait untuk melakukan karakterisasi pada modul $C P$-injektif. Berikut didefinisikan

Definisi 5 [4] Misalkan $M$ adalah modul atas $R$ dan $N$ adalah submodul dari $M$. Submodul tak nol $N$ disebut submodul essensial dari $M$, ditulis $N \operatorname{ess}_{R} M$ atau $N$ ess $M$, jika dan hanya jika $X \cap N \neq 0$ untuk setiap $X$ submodul tak nol dari $M$. Dalam hal ini $M$ disebut essential extension dari $N$.

Berikut diberikan beberapa contoh modul dan essential extensionnya.

Contoh 1 Misalkan $M$ sebarang modul atas $R$. Modul M adalah essential extension dari dirinya sendiri, ditulis $M$ ess $M$.

Contoh 2 Submodul $n \mathbb{Z}$ adalah submodul essensial dari $\mathbb{Z}$ untuk sebarang $0 \neq n \in \mathbb{Z}$.

Contoh 3 Misalkan $R$ lapangan. Bentuk modul $R[X]$ atas $R[X]$. Didefinisikan himpunan $P_{n}[X]=$ $\left\{a_{n} X^{n}+a_{n+1} X^{n+1}+\ldots+a_{m} X^{m} \mid\right.$ dengan $n, m \in \mathbb{N} \cup\{0\}, n \leq m, a_{i} \in R$ untuk $i \in\{n, \ldots, m\}$ submodul atas $R[X]$. Sehingga $P_{n}[X]$ ess $R[X]$ untuk $n \in \mathbb{N} \cup\{0\}$.

Salah satu sifat submodul essensial terkait dengan homomorfisma dijelaskan pada lemma berikut ini.

Lemma 4 Diketahui $M$ adalah $R$-modul dan $N$ submodul $M$, submodul $N$ adalah submodul essensial dari $M$ maka untuk setiap $R$-modul $L$ dan $R$-homomorfisma $\varphi: M \longrightarrow L$ berlaku jika $\left.\varphi\right|_{N}$ injektif maka $\varphi$ injektif

Bukti. Misalkan $M$ essensial extension dari $N$. Akan ditunjukkan bahwa untuk sebarang $R$ modul $L, R$-homomorfisma $\varphi: M \longrightarrow L$ injektif jika $\left.\varphi\right|_{N}$ injektif. Diketahui $\left.\varphi\right|_{N}$ injektif maka $\left.\operatorname{Ker} \varphi\right|_{N}=\{0\}$. Akan ditunjukkan $\operatorname{Ker} \varphi \cap N=0$. Ambil $a \in \operatorname{Ker} \varphi \cap N$, maka $a \in \operatorname{Ker} \varphi$, akibatnya $\varphi(a)=0$. 
Sementara itu, $a \in N$, akibatnya $\left.\varphi\right|_{N}(a)=l \in L$. Karena $N \subset M$ maka $0=\varphi(a)=$ $\left.\varphi\right|_{N}(a)=l$. Karena $\left.\varphi\right|_{N}$ injektif haruslah $a=0$. Akibatnya, $\operatorname{Ker} \varphi \in N=0$. Jelas $\operatorname{Ker} \varphi$ submodul dari $M$. Karena $M$ essensial ekstention dari $N$ berlaku jika $\operatorname{Ker} \varphi \cap N=0$ maka $\operatorname{Ker} \varphi=0$. Akibatnya $\varphi$ injektif.

Dengan memanfaatkan $R$-monomorfisma diperoleh definisi submodul- $C P$ yang termuat dalam Definisi berikut.

Definisi 6 [4] Submodul $A$ dari $R$-modul $B$ dikatakan $C P$ jika pemetaan inklusi $A \hookrightarrow B$ adalah $C P$.

Misalkan $M$ adalah suatu $R$-modul dan $N$ adalah suatu $C P$-submodul dari $M$. Modul $M$ disebut essensial $C P$-ekstension dari $N$, jika tidak terdapat submodul taknol $K$ dari $M$ sehingga $K \cap N=0$ dan $(K+N) / K$ adalah $C P$-submodul dari $M / K$.

Diketahui $M$ adalah $R$-modul dan $N$ submodul $M$, submodul $N$ adalah submodul essensial dari $M$ maka untuk setiap $R$-modul $L$ dan $R$-homomorfisma $\varphi: M \longrightarrow L$ berlaku jika $\left.\varphi\right|_{N}$ injektif maka $\varphi$ injektif. Dengan konsep yang serupa, untuk essensial CP-extension kita peroleh sifat sebagai berikut.

Lemma 5 [4] Misalkan $N$ adalah $C P$-submodul dari $R$-modul $M$, modul $M$ adalah essensial $C P$-extension dari $N$ maka untuk setiap homomorfisma $\varphi: M \longrightarrow L$ sehingga $\varphi \mid N$ adalah CP-homomorfisma, maka $\varphi$ injektif.

Lemma 6 [4] Misalkan $N$ adalah $C P$-submodul dari R-modul M. Maka, terdapat submodul $K$ dari $M$ sehingga

1. $K \cap N=0$,

2. $(K+N) / K$ adalah $C P$-submodul dari $M / K$,

maka $M / K$ adalah suatu CP-ekstension dari $(K+N) / K$.

Lemma 7 [4] Misalkan $f: E \longrightarrow E^{\prime}$ adalah suatu R-monomorfisma. Terdapat modul ekstent ion $E^{\prime \prime}$ dari $E$ dan isomorfisma $g: E^{\prime \prime} \longrightarrow E^{\prime}$ yang memperluas homomorfisma $f$ sehingga $g(e)=f(e)$ untuk setiap $e \in E$.

Jika $M$ adalah suatu $R$-modul maka terdapat suatu ekstension $D$ dari $M$ sehingga $D$ bersifat $C P$-injektif dan $D$ memuat $M$ sebagai $C P$-submodul. Untuk buktinya dapat dilihat pada Lemma berikut ini.

Lemma 8 [4] Misalkan $M$ adalah $R$-modul. Terdapat suatu extension $D$ dari $M$ sehingga $D$ bersifat CP-injektif dan D memuat $M$ sebagai CP-submodul.

Sekarang, akan disajikan karakterisasi dari modul $C P$-injektif terkait essensial $C P$-extension sejati. Akan ditunjukkan suatu $R$-modul $D$ merupakan $C P$-injektif jika dan hanya jika $D$ tidak memiliki essensial CP-extension sejati. 
Teorema 3 Misalkan D adalah R-modul. Maka pernyataan berikut ekivalen:

\section{D adalah CP-injektif.}

2. Untuk sebarang CP-monomorfisma $f: A \longrightarrow B$, setiap homomorfisma dari $A$ ke $D$ bisa diperluas menjadi homomorfisma dari $B$ ke $D$.

3. Setiap barisan eksak $C P 0 \longrightarrow D \longrightarrow M \longrightarrow N \longrightarrow 0$ splits.

4. D adalah jumlah langsung dari setiap $R$-modul L sehingga $D$ adalah CP-submodul dari $L$.

5. D tidak memiliki esensial CP-ekstension sejati.

Bukti. $(1 \longrightarrow 2)$

Diketahui $D$ adalah $C P$-injektif. Karena $0 \longrightarrow A \stackrel{f}{\rightarrow} B \stackrel{g}{\rightarrow} B / f(A) \longrightarrow 0$ eksak $C P$, maka $0 \longrightarrow \operatorname{Hom}(B / f(A), D) \stackrel{g^{\prime}}{\rightarrow} \operatorname{Hom}(B, D) \stackrel{f^{\prime}}{\rightarrow} \operatorname{Hom}(A, D) \longrightarrow 0$ eksak. Perhatikan bahwa untuk setiap $\tau \in \operatorname{Hom}(A, D)$ dan karena $f$ injektif maka dapat dibentuk

$$
\begin{aligned}
\sigma^{\prime}: \operatorname{Im}(f) & \longrightarrow D \\
b & \longmapsto \tau \circ f^{-1}(b) .
\end{aligned}
$$

Karena $0 \longrightarrow \operatorname{Hom}(B / f(A), D) \stackrel{g^{\prime}}{\rightarrow} \operatorname{Hom}(B, D) \stackrel{f^{\prime}}{\rightarrow} \operatorname{Hom}(A, D) \longrightarrow 0$ eksak, maka untuk sebarang $\tau \in \operatorname{Hom}(A, D)$ terdapat $\sigma \in \operatorname{Hom}(B, D)$. Sehingga $f^{\prime}(\sigma)=\tau$. Perhatikan bahwa $\sigma^{\prime}=\left.\sigma\right|_{i m(f)}$, artinya sebarang $\operatorname{Hom}(A, D)$ dapat diperluas menjadi $\operatorname{hom}(B, D)$.

$$
(2 \longrightarrow 3)
$$

Diberikan $f: A \longrightarrow B$ homomorfisma. Maka sebarang $\operatorname{Hom}(A, D)$ dapat diperluas menjadi $\operatorname{Hom}(B, D)$. Pandang

$$
0 \longrightarrow D \stackrel{f}{\rightarrow} M \stackrel{g}{\rightarrow} N \longrightarrow 0
$$

eksak $C P$. Sehingga $f: D \longrightarrow M$ adalah suatu $C P$-homomorfisma. Berdasarkan 2. dapat diperluas menjadi

$$
\sigma: M \longrightarrow D
$$

Karena $\tau$ pada, maka $\sigma$ juga pada. Sehingga

$$
\begin{aligned}
\gamma: M & \longrightarrow D \oplus N \\
m & \longmapsto \sigma(m) \oplus g(m)
\end{aligned}
$$

Akan ditunjukkan $\gamma$ pada. Ambil sebarang $d \oplus n \in D \oplus N$. Karena $\sigma$ pada maka $\exists m \in M$ sehingga $\sigma(m)=d$. Karena $g$ pada maka $\exists m \in M$ sehingga $g(m)=n$. Sehingga $\gamma(m)=$ $\sigma(m) \oplus g(m)$.

$$
(3 \longrightarrow 4)
$$

Karena $0 \longrightarrow D \longrightarrow M \longrightarrow N \longrightarrow$ ) splits maka $M \cong D \oplus N$. D adalah $C P$-submodul dari $R$-modul $L$, maka $0 \longrightarrow D \stackrel{f}{\rightarrow} L \longrightarrow L / i m\{f\} \longrightarrow 0$. Karena 3. maka

$$
L \cong D \oplus L / i m\{f\}
$$


Jadi, $D$ adalah suku langsung dari $L$.

$$
(4 \longrightarrow 5)
$$

Misalkan $M$ essensial $C P$ ekstension dari $D$. Akibatnya tidak ada submodul tak nol $K$ dari $M$ sedemikian hingga $K \cap D=0$ dan $K+D / K$ adalah $C P$-submodul dari $M / K$. Berdasarkan 4. $M=L+D$ dan $L \cap D=0$. Perhatikan bahwa $L+D / L=M / L$. Karena $M$ essensial $C P$ dari $D$ artinya jika $L \cap D=0$ dan $L+D / L$ adalah $C P$ submodul dari $M / K$ maka haruslah $L=0$. Jadi terbukti $D=M$.

$$
(5 \longrightarrow 4)
$$

Misalkan $L$ adalah $C P$-extension sejati dari $D$. Berdasarkan Lemma 6 terdapat submodul $K$ dari $L$ sehingga $D+K / K$ adalah $C P$-submodul dari $L / K$. Dengan kata lain, $L / K$ adalah $C P$ - extension $D+K / K$ dengan $D \cap K=0$. Tetapi $D$ tidak punya essensial $C P$-ekstension sejati. Berarti $L=D$. Maka

$$
\begin{aligned}
K & =0 ; \\
D+D & =L ; \\
D \oplus K & =L .
\end{aligned}
$$

Jadi $D$ adalah suku langsung dari setiap $R$-modul $L$ sehingga $D$ adalah $C P$-submodul dari $L$.

$$
(4 \longrightarrow 1)
$$

$D C P$-submodul dari $L$ dan $L=D \oplus K$.

Berdasarkan Lemma 4. modul $L$ adalah $C P$-injektif. Akibatnya berdasarkan Lemma $1 \mathrm{~K}$ dan $D$ adalah $C P$-injektif.

Pengkajian yang telah dilakukan menunjukkan bahwa jika $M$ adalah suatu $R$-modul maka terdapat suatu $C P$-Injektif $R$-modul $D$. Salah satu sifat dari modul $C P$-injektif jika dikaitkan dengan essensial $C P$-extension sejati adalah bahwa $R$-modul $D$ merupakan $C P$-injektif jika dan hanya jika $D$ tidak memiliki essensial $C P$-ekstension sejati.

\section{KESIMPULAN DAN PENELITIAN LANJUTAN}

Pada penelitian ini telah dilakukan kajian mengenai modul $C P$-Injektif meliputi pemetaan bilinear, hasilkali tensor, pemetaan natural, barisan eksak, barisan eksak cyclically pure, monomorfisma cyclically pure, submodul cyclically pure, pemetaan inklusi, dan modul injektif. Pengkajian yang telah dilakukan menunjukkan bahwa jika $M$ adalah suatu $R$-modul maka terdapat suatu $C P$-Injektif $R$-modul $D$.

Dalam penelitian ini penulis mengkaji salah satu karakterisasi dari modul $C P$-injektif yaitu suatu $R$-modul $D$ merupakan $C P$-injektif jika dan hanya jika $D$ tidak memiliki essensial $C P$-ekstension sejati. Penelitian lebih lanjut yang menarik untuk dilakukan adalah melakukan karakterisasi modul $C P$-injektif terkait dengan jumlah langsung dari modul-modul yang berbentuk $\operatorname{Hom}_{R}(L, E)$ dengan $E$ adalah $R$-modul injektif dan $L$ adalah jumlah langsung dari family dari modul siklis yang dibangun secara hingga. 


\section{REFERENSI}

[1] J.Xu, Flat Covers of Modules, Lecture Notes in Math. Berlin: Springer Vol 1634, 1996.

[2] L. Melkersson, "Small Cofinite Irreducibles", J. Algebra, 1997.

[3] D.S. Passman, A Course In Ring Theory. USA: AMS, 1991.

[4] K. Divaani-Aazar, M.A. Esmkhani, M.Tousi., "Some Criteria of Cyclically Pure Injective Modules", Proc. Amer. Math. Soc., in press, 2005.

[5] D.W. Sharpe, P. Vamos, Injective Modules, Cambridge Tracts in Math. Cambridge Univ. Press Vol. 62, 1972.

[6] K. Divaani-Aazar, M.A. Esmkhani, M.Tousi., "Two Characterizations of pure injective Modules", Proc. Amer. Math. Soc.,

[7] F.W. Anderson, K.R Fuller, Rings and Categories of Modules. New York: Springer, 1974.

[8] Herzog, Ivo, "Pure Injective Envelopes", Journal of Algebra and Its Applications Vol 02 No. 04, 2003.

[9] M. Prest, Model Theory and Modules, Lecture Notes in Math. London: Cambridge Univ Vol 130, 1988.

[10] Yokonuma, Takeo, Tensor Spaces and Exterior ALgebra. Providence: AMS, 1992. 